\title{
MAPPING AND VISUALISING DIGITAL PRESENCE
}

\author{
Kaiti Papapavlou $^{\dagger *}$, Olga Linardou ${ }^{\dagger *}$, Ava Fatah gen. Schieck ${ }^{\dagger}$, Alasdair Turner ${ }^{\dagger}$ \\ ${ }^{\dagger}$ Bartlett Graduate School, UCL, UK \\ These authors declare equal contribution ( kaitipapapavlou@gmail, olga.linardou@gmail)
}

Keywords: Interaction space, Physical and Digital Space Activation, New Technologies, Bluetooth \& device naming.

\begin{abstract}
Considering the complexity of the urban context and the forms of communication that take place in it, this article discusses the experience of latent intelligent environments which are generated through the use of new technologies in the city field. We will report briefly on a pilot study (Bath, UK) in which we investigate how digital presence affects social communication. We conclude by considering (a) whether the individuals' behaviour and the city organism were affected or re-formed by the exposure of information that referred to their characteristics and activities, and (b) the ways in which the received raw data can be transformed into a meaningful form of information that can be embedded in intelligent environments.
\end{abstract}

\section{Introduction}

Computational force is unnoticeably embedded in the everyday world, creating an activity network, a new background where new behaviors emerge. McCullough refers to this new layer as a "quiet architecture" [1] within which we interact by forming new relations and novel qualities of space. In that way digital technologies extend the reach of architecture by demanding a multidisciplinary synergy in the design of environments that facilitate socially embedded human-technology interactions. In this paper we present initial results of a pilot study conducted in the city of Bath as part of the project 'Cityware' which explores the impact of emergent

technologies on the evolving forms of communication and socialization and on its relation to the properties of architectural space [2]. The notion of permanence is increasingly challenged by the nonmaterial representation of events and experiences [3]. Our aim was to investigate how the digital 'layer' and the triggered social interactions can be captured, documented and represented to help us understand people's performance and interaction as defining elements of a digital culture within public space.

\section{Methodology}

\section{2. a. Design of the experiment}

Our intention was to activate space not by architectonic, but by electronic artifacts. According to Tschumi, rather than questioning the technology of construction, architects should be involved in the construction of technology [3], as the new computerized processes and integrated programmed systems already affect in a high degree the design and building of architectural space.

In our experiment, we used the Processing language to test and observe the implementation of new technologies using Bluetooth scanning to capture and represent the digital co-presence through the visualisation of the data. The property of mobility differentiates Bluetooth from static WiFi Technology; Bluetooth enabled mobile devices follow people's movements, revealing patterns and mapping preferences, which constitute latent elements of social communication and interactivity.

Each mobile phone with Bluetooth technology, if configured appropriately, broadcasts within 5-10 meters a Bluetooth MAC address, the device name, and the device type. The MAC address is a number unique to the particular device, whereas the device name can be set at the user's discretion; e.g., "Tony's Nokia". By recording and projecting the range of names in public, we tried to explore whether the visualization of personal information could cause patterns of interaction.

\section{2. b. Location and Crowd activity}

Our basic setup was replicated across three indoor and one outdoor locations with different social activity: a pub/club, a café in the city of Bath, at the entrance of a fast-food restaurant also in Bath, and in a restaurant in Weimar, Germany. A computer was constantly recording the number and the names of Bluetooth devices within a 10-meter range. We captured the data and visualized the digital co-presence using 
Processing as a graphic method of representation, projecting the result on a noticeable place in the three different spaces. We will focus mostly on the data collected from two locations in Bath (pub/club and café). In Weimar as well as at the outdoor location in Bath there was no response from the public (no Bluetooth names were detected).

During the projection at the club in Bath, the casually charged atmosphere made the people somewhat receptive to the projection Whereas at the café in the same city, the atmosphere was just as casual but more reserved. Social interaction was very limited. Having a projection in such a space was seen as little queer and to a certain extent, rather intrusive. Especially when they. observed that their Bluetooth name was scanned and displayed.

\section{2. c. Placement of the projection surface}

At the club, the projection surface was placed on the far end of the room, where the projection could be seen directly from the entrance of the space. Although the projection was sufficiently large comparing to the space, it was actually remote. Thus, the projection was perceptible, yet it did not intrude or impose itself onto the space and its activities (Figure 1). While there was a dedicated projection space in the club, the projection at the cafe was done on a less conspicuous section of the space. The projection surface was on the same plane with the entrance; this meant that one would not be immediately aware of it as one entered the room (Figure 2).

At the café-restaurant in Weimar the projection was made on a wall facing the entrance. It was clearly visible by the people entering the place as well by the people heading to the first floor where the gallery was hosting the opening of two artists exhibition. Nevertheless, no one seemed to be interested in the projection. One reason can be that there were only three names detected (low level of Bluetooth activity). Another reason might be the possibility that visitors may think that the projection could be part of the exhibition; they took a look and then continued their way to the gallery (Figure 3). Considering the outdoor projection we can mention that it didn't succeed mostly due to lack of equipment, and the incapability of our scanning tool to handle our setting. Our aim was to create a "playground" for the pedestrians on their way to their destination (Figure 4).

\section{2. d. Data Collection}

The method we used to scan for Bluetooth devices generates discrete data about the presence of devices in the environment. Data were recorded throughout various sessions over the course of two days. A visualization of our data can be seen in Figure 5 . Whenever a device was detected, its "Name" was displayed and floated around the display space. At the same time, a "Tag" appeared and tried to catch the Name. With several Names appearing along with several Tags, the visualization became an abstract, yet seemingly organic entity; a representation of the ever- evolving social network, unified by the physical space. As soon as a Bluetooth signal was not detected, the Tag faded out and disappeared from the screen. In this way we projected all devices that were present at the same time at the same place (Table 1 ).

Our intention was not only to map digital presence but also to activate the participants' performance. In that way our aim was to provoke the emergence of nonmaterial relationships and observe their impact on shaping the interaction space [4]. In order to trigger people's reactions we decided to make the model more interactive, and we therefore attached "Tags" on each name (Picture 1, e.g: hey! Rocks!). To that end, the visual representation was not limited to the presentation of the 'Name' of each Bluetooth device assigned by its user, but instead, we intervened in the designing method itself to make people participate and provoke reactions. Thus, every 'Name' was linked to a 'Tag' (e.g. an expression, a social description) that we randomly chose. By establishing an explicit link between the Tag and the Name, we expected to encourage the emergence of novel social behaviors and interactions among the participants (Table 1).

In order to have a more in depth insight of how the experiment affected the participants and how they felt about their personal data been projected publicly, we distributed questionnaires and also conducted brief interviews with them.

To recruit participants, people in both locations were simply asked "Have you got Bluetooth?" As this study was not seeking to capture data on why individuals didn't have Bluetooth or didn't use it, persons in those categories were not invited to participate. Twenty-five questionnaires were collected, ten during the first night at the club and 15 at the café, in Bath. At the results' section below, we present the recorded feedback to the questionnaires.

\section{Results}

\section{Observed Reactions}

Overall, we observed that the linkage of a "User Name" to an assigned social Tag triggered mixed reactions. In the club when people were faced with the projected visualization of Bluetooth names of people present in the physical space, various social interactions were triggered. For example, some people used the projection as an interactive message board by means of their mobile phone, and most of them found the process playful and entertaining; they kept changing their Bluetooth names and waited to see the result on the screen. For instance, from Table 1, we can see how "Optimus prime" turned to "Hi camera lady" and from an unknown device name to "Mcraith wants jesson”.

As related to the questionnaires, before describing people's responses, it is worth mentioning that it was mainly people aged 21 to 25 who were broadcasting device names (older people tended to suggest that they 
did not know the technology well and were not inclined to use it). To the question 'How do you feel about your name made public and interacted with?' 8 people were comfortable and only 2 were opposed, although there were two people (one 21 and one 26 years old) who reacted in an extreme way and expressed their anger about this type of surveillance. More precisely, the 21 years old was strongly opposed to the way technology intervened to hers and her friends' personal information. At the same time, to thequestions 'Do you feel this kind of interaction can have an impact on the space' and 'Does it enhance your experience of that space', only 11 out of 25 were positive and they expressed their affirmative feelings about the future of technology and its impact to space, as they were not able to imagine the future influence of such applications to the environment.

In conclusion, at all locations, most people liked the experiment and wanted to participate in the kind of interplay offered; according to Gausa M. et. al.'s classification, they were interactive, open to communicate and accepted the rules of this type of communication [5]. At the same time others were denouncing not only the exposure of their personal data, but also our provoking intervention to their digital identity.

\section{Conclusions-Discussion}

By conducting the described experiment, we tried to study the influence of new technologies on forming human behavior and observe the ways in which people's performance in public mediated space define a digital culture.

In conclusion, our paradigm was successful in triggering responses. Many factors may influence these responses as it became evident by the mixed and sometimes ambivalent reactions. We think that age, habituation with the use of digital media, socioeconomic status, and other factors, as well as the established social use of the physical context/space affected/formed the different types of people's reaction. To sum up, we could say that Bluetooth operates between the participants' mobile phones as a partially embodied medium, making it a distinctive paradigm of socially and physically embedded communication [6]. This study shows that, in general, the sharing of media has led to an electronic projection of identity and presence through the Bluetooth channel, a presence which runs in parallel to the physical information flows within face-to-face engagements and it is not only a controlled (intentional) but also an uncontrolled projection of our autobiography [7].

Is the creation of simple mechanisms that can recognize structures of human behaviors' through mapping this fusion of data, able to form dynamic events in the social context? And in extension are these events capable of shaping highly interactive environments such as intelligent environments? Our belief is that designing interfaces which are more immersive, more intelligent and more interactive could change in a fertile way the human-machine relationship.

It would be important to examine in greater detail which factors influence people's behavior and to what degree, and provide a motivation to change the way they communicate and engage with others in various environments. Our next aim will be to develop empirically testable hypotheses to evaluate and possibly quantify the role of different factors relating to the participants and the context conditions, which will be systematically investigated in controlled experiments. Reflecting on the pilot data of our research, which indicate the use of new media in everyday life, we should expand our inferences and refer to their implementation in shaping architecture-including the new computerized processes already altering building and design- and social interaction.

\section{Pictures and tablesFigure}

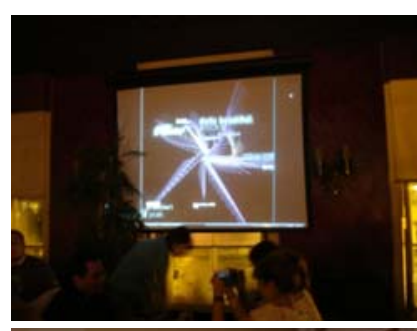

Figure 1. Projection at the Pub/Club [22:45pm, 13 Dec. 2007, Bath]

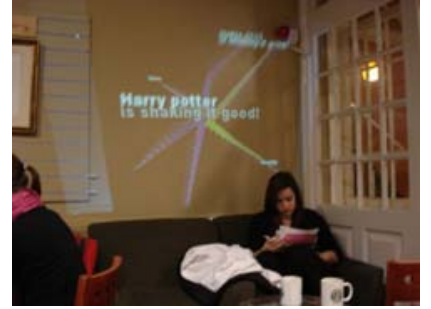

Figure 2. Projection at Café [16:25 pm, 14 Dec. 2007, Bath]

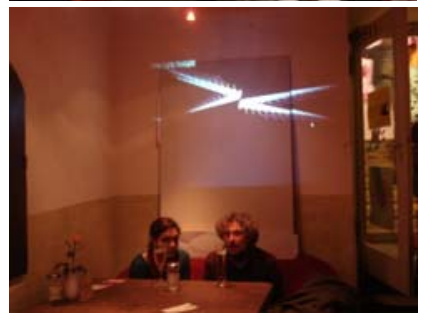

Figure 3. Projection at the Cafe [20:30 pm, 19 Jan. 2008, Weimar]

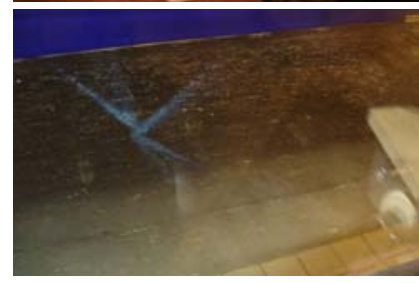

Figure 4. Outdoor Projection $[17: 10 \mathrm{pm}$, 13 Dec. 2007Bath]

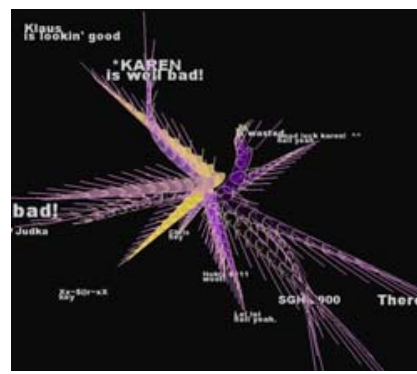

Figure 5: The

Visualization of the

Digital Data at Starbucks Cafe [16:35 pm, 14 Dec. 2007] 


\begin{tabular}{|c|c|c|c|c|}
\hline Time sessions & $\begin{array}{l}\text { No of people } \\
\text { present in } \\
\text { the club }\end{array}$ & $\begin{array}{l}\text { No of scanned } \\
\text { devices }\end{array}$ & User's device's name & Tag name \\
\hline 22:00-22:15 & 25 & 14 & $\begin{array}{l}\text { Hello beautiful! } \\
\text { Davey-G } \\
\text { Jodie } \\
\text { Jx } \\
\text { W880 } \\
\text { JawaDemam } \\
\text { Scarlet x x } \\
\text { Man Mountain } \\
\text { Kurva! } \\
\text { Gorgeous } \\
\text { Dick Willie Cox } \\
\text { Princess } \\
2 \text { unknown }\end{array}$ & $\begin{array}{l}\text { Is looking good } \\
\text { Woot! } \\
\text { Hey } \\
\text { ROCKS! } \\
\text { Is bitchin'! }\end{array}$ \\
\hline 22:15-22:30 & 38 & 10 & $\begin{array}{l}\text { Pleb Nokia } 6300 \\
\text { SEX APPEAL BUT DESPERATE PLZ } \\
\text { Gem } \\
\text { Abel } \\
\text { Lonsdale is GAY } \\
\text { Optimus Prime } \\
4 \text { unknown }\end{array}$ & $\begin{array}{l}\text { Smelly } \\
\text { Is well bad } \\
\text { - } \\
\text { Is wasted }\end{array}$ \\
\hline 22:30-22:45 & 45 & 13 & $\begin{array}{l}\text { Everyone wants lonsdale! (former Davey-G) } \\
\text { Jodie } \\
\text { Get ur spade out! (unknown before) } \\
\text { Rob N Roll (unknown before) } \\
\text { Hey camera lady...(former Optimus Prime) } \\
\text { Pete has ten inches?(former Davey-G) } \\
\text { Jesson is Gay (former Gem) } \\
\text { Newman is a sex pest (unknown before) } \\
\text { Likes To Lick (former Dick Willie Cox) } \\
\text { BP4232-MBPRO-4 } \\
\text { Jo wants to shag Dom (former Lonsdale is GAY) } \\
\text { Rob N Fuckin Roll (former Rob N Roll) } \\
1 \text { unknown }\end{array}$ & $\begin{array}{l}\text { Hell yeah } \\
\text { Is shaking it good } \\
\text { Hey } \\
\text { ROCKS! } \\
\text { Smelly }\end{array}$ \\
\hline 22:45-23:00 & 42 & 10 & $\begin{array}{l}\text { Helphire are shite } \\
\text { Mcraith wants jesson } \\
\text { I want cock! } \\
\text { Theres only one! } \\
6 \text { unknown }\end{array}$ & $\begin{array}{l}\text { Woot! } \\
\text { Hey } \\
\text { Is well bad } \\
\text { - } \\
\text { Is shaking it good } \\
\text { - }\end{array}$ \\
\hline
\end{tabular}

Table 1. Data collected from the projection at the Club [13 Dec. 2007, Bath]

\section{Acknowledgements}

We would like to acknowledge the efforts of all our fellow students and especially Adi Ahmad and Olivier Ottevaere who worked on the Processing code as well as on the conduction of the experiment. We thank Vassilis Kostakos for his support. This project was developed as part of the MSc Adaptive Architecture and Computation at UCL. The project was partially funded by Cityware: Urban design and pervasive systems (grant EP/C547683/1).

\section{References}

[1] McCullough M., Flow Needs Fixity, Amsterdam, 2002:

http://flow.doorsofperception.com/content/mccullough _trans.html, access on 10-11-2007.
[2] Fatah gen. Schieck, A, Penn, A, Kostakos, V, O’Neill, E, Kindberg, T, Stanton Fraser, D, and Jones, T, 2006,Design Tools for Pervasive Computing in Urban Environment. In proceedings 8th International Conference on Design \& Decision Support Systems in Architecture and Urban Planning, Eindhoven, Springer, NL, 2006.

[3] Tschumi B., Event Cities (Praxis), MIT Press, London, 1994.

[4] O’Neill, E., P. Johnson and H. Johnson, Representations and user-developer interaction in cooperative analysis and design. Human-Computer Interaction, 14 (1), 1999.

[5] Gausa M. et. al., Ed., The Metapolis Dictionary of Advanced Architecture, ACTAR: Barcelona, 2003.

[6]Kindberg, T., and Jones, T., "Merolyn the Phone": A study of Bluetooth naming practices, Ubicomp 2007, Innsbruck, 318-335, 2007.

[7] Fatah gen. Schieck, A., Kostakos, V., Exploring digital encounters in the city. In The 25th International Conference on Computer \& Human Interactions CHI 2007, San Jose, USA.(position paper: Shared Encounters) 2007. 